\title{
Erratum to: Administration of 17 $\beta$-Estradiol Improves Motoneuron Survival and Down-regulates Inflammasome Activation in Male SOD1(G93A) ALS Mice
}

\author{
Marius Heitzer $^{1}$ • Sarah Kaiser ${ }^{1}$ - Mithila Kanagaratnam ${ }^{1}$ - Adib Zendedel ${ }^{1,2}$. \\ Philipp Hartmann ${ }^{1}$. Cordian Beyer ${ }^{1,3} \cdot$ Sonja Johann ${ }^{1}$
}

Published online: 19 January 2017

(C) Springer Science+Business Media New York 2017

Erratum to: Mol Neurobiol

DOI: $10.1007 / \mathbf{s} 12035-016-0322-4$

The original version of this article unfortunately contained mistakes in Figures.

In Figure 4a and 5a, the unit "micro" at scale bars were unconverted. Instead of micrometer $(\mu \mathrm{m})$, it was published as millimeter $(\mathrm{mm})$.

The corrected Figure 4 and 5 are hereby given below.

The original article was corrected.

The online version of the original article can be found at http://dx.doi. org/10.1007/s12035-016-0322-4.

Sonja Johann

sjohann@ukaachen.de

1 Institute of Neuroanatomy, Faculty of Medicine, RWTH Aachen

University, Wendlingweg 2, 52074 Aachen, Germany

2 Department of Anatomical Sciences, Faculty of Medicine, Guilan

University of Medical Sciences, Rasht, Iran

3 JARA-BRAIN, 52074 Aachen, Germany 
Fig. 4

a
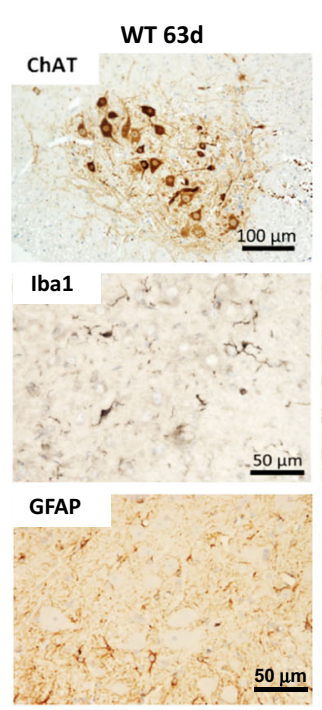

d

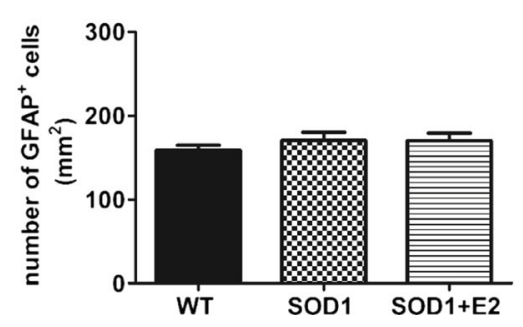

b
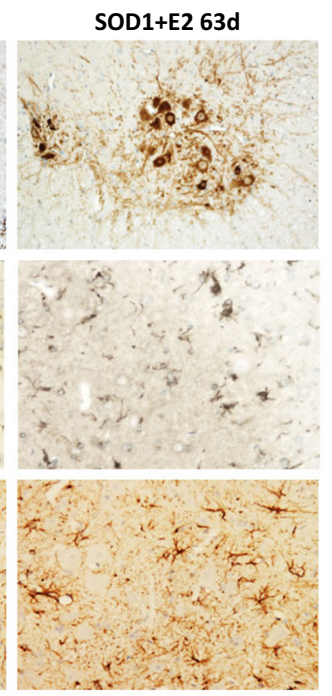

e

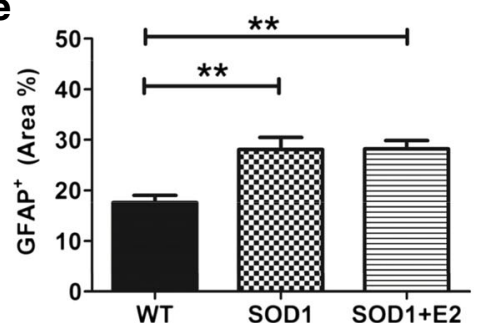


Fig 5

a

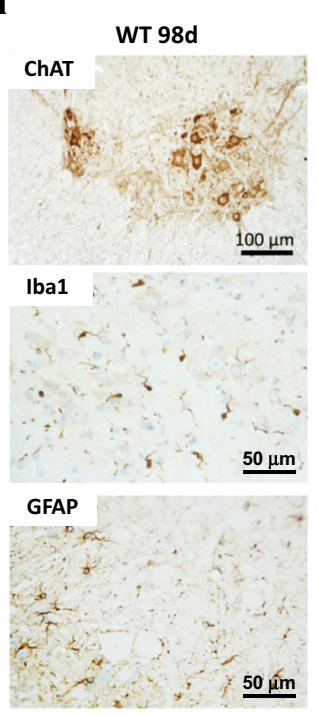

d

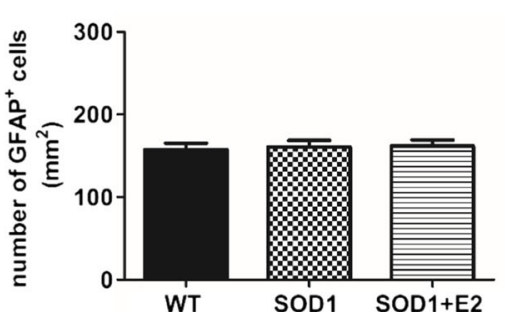

symptomatic male

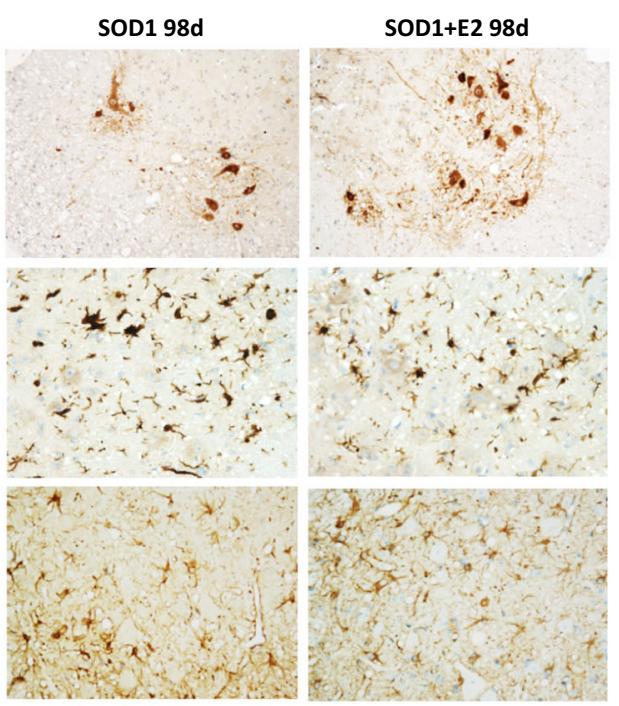

b

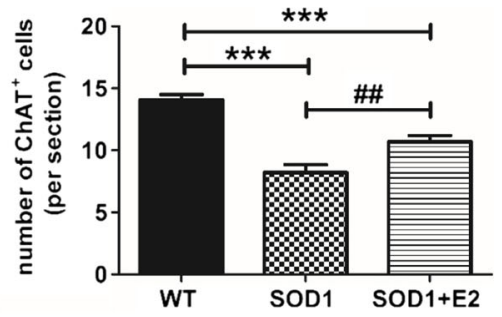

C

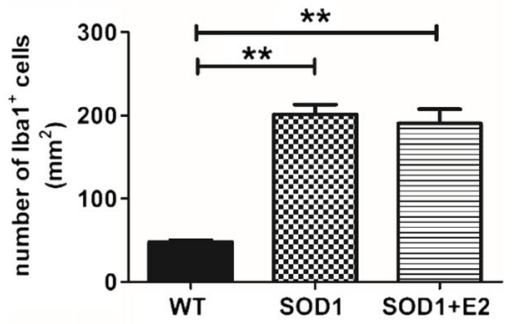

e

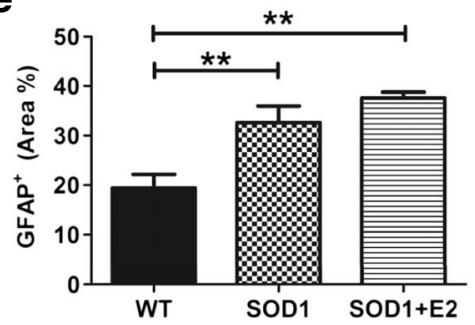

